\title{
Detecting the feeding habitat zone of albacore tuna (Thunnus alalunga) in the southern Indian Ocean using multisatellite remote sensing data
}

\author{
Sandipan Mondal \\ National Taiwan Ocean University, Keelung, Taiwan, ROC \\ Yang-Chi Lan \\ Taiwan Fisheries Research Institute, Kaohsiung, Taiwan, ROC \\ Ming-An Lee \\ National Taiwan Ocean University, Keelung, Taiwan, ROC, malee@ntou.edu.tw \\ Yi-Chen Wang \\ National Taiwan Ocean University, Keelung, Taiwan, ROC \\ Bambang Semedi \\ Brawijaya University, Malang, East Java, Indonesia
}

See next page for additional authors

Follow this and additional works at: https://jmstt.ntou.edu.tw/journal

Part of the Fresh Water Studies Commons, Marine Biology Commons, Ocean Engineering Commons, Oceanography Commons, and the Other Oceanography and Atmospheric Sciences and Meteorology Commons

\section{Recommended Citation}

Mondal, Sandipan; Lan, Yang-Chi; Lee, Ming-An; Wang, Yi-Chen; Semedi, Bambang; and Su, Wan-Ya (2022) "Detecting the feeding habitat zone of albacore tuna (Thunnus alalunga) in the southern Indian Ocean using multisatellite remote sensing data," Journal of Marine Science and Technology. Vol. 29: Iss. 6, Article 8.

DOI: $10.51400 / 2709-6998.2559$

Available at: https://jmstt.ntou.edu.tw/journal/vol29/iss6/8

This Research Article is brought to you for free and open access by Journal of Marine Science and Technology. It has been accepted for inclusion in Journal of Marine Science and Technology by an authorized editor of Journal of Marine Science and Technology. 
Detecting the feeding habitat zone of albacore tuna (Thunnus alalunga) in the southern Indian Ocean using multisatellite remote sensing data

Authors

Sandipan Mondal, Yang-Chi Lan, Ming-An Lee, Yi-Chen Wang, Bambang Semedi, and Wan-Ya Su 


\title{
Detecting the Feeding Habitat Zone of Albacore Tuna (Thunnus Alalunga) in the Southern Indian Ocean using Multisatellite Remote Sensing Data
}

\author{
Sandipan Mondal a, Yang-Chi Lan ${ }^{b}$, Ming-An Lee ${ }^{a, c, *}$, Yi-Chen Wang ${ }^{a}$, \\ Bambang Semedi ${ }^{d}$, Wan-Ya Su ${ }^{a}$ \\ a Department of Environmental Biology and Fisheries Science, National Taiwan Ocean University, Keelung, Taiwan, ROC \\ ${ }^{\mathrm{b}}$ Coastal and Offshore Resources Research Center, Taiwan Fisheries Research Institute, Kaohsiung, Taiwan, ROC \\ ${ }^{c}$ Center of Excellence for Ocean Engineering, National Taiwan Ocean University, Keelung, Taiwan, ROC \\ ${ }^{\mathrm{d}}$ Fisheries and Marine Science Faculty, Brawijaya University, Malang, East Java, Indonesia
}

\begin{abstract}
Remote sensing is an effective method for identifying potential feeding habitat zones. Spatial and temporal distribution patterns of albacore (ALB) tuna were studied using Taiwan longline fisheries data from 2009 to 2014 . A generalized additive model (GAM) was used to compile a fishery database and statistically explore the relationship between distribution and environmental factors. Sea surface temperature (SST), sea surface chlorophyll-a concentration (SSC), sea surface salinity (SSS), sea surface height (SSH), mixed layer depth (MLD), and eddy kinetic energy (EKE) were examined. The results indicated SST as the largest contributor on ALB distribution, followed by SSS and SSC. Catches per unit effort (CPUE) values indicated that ALB tuna were primarily distributed at $20^{\circ} \mathrm{E}-110^{\circ} \mathrm{E}$ and $25^{\circ} \mathrm{S}-40^{\circ} \mathrm{S}$. The $\mathrm{SST}$ and SSS ranges for higher ALB abundance were $17-19^{\circ} \mathrm{C}$ and $35.1-35.5 \mathrm{psu}$, respectively. SSC was positively related to CPUE as a result of ALB tuna habits in the current location during the study period $\left(0.1-0.25 \mathrm{mg} \mathrm{m}^{-3}\right)$. The predicted CPUE indicated that the potential feeding habitat zones were $35^{\circ} S-40^{\circ} S$ and $25^{\circ} S-30^{\circ} S$ during $M a r c h$ and April-August, respectively. These findings provide preliminary insight into the key environmental features affecting the ALB distribution in the southern Indian Ocean.
\end{abstract}

Keywords: Albacore, Sea surface temperature, Sea color, Generalized additive model, Long-line

\section{Introduction}

$\mathrm{T}$ una is a highly migratory species with very high economic value. In past decades, albacore (ALB) tuna alone has accounted for approximately $84 \%$ of total temperate tuna catches in the Indian Ocean; thus, it is one of the primary commercially targeted species [1]. Furthermore, ALB tuna has long been the subject of scientific research. The species is widely distributed in the three major oceans from $50^{\circ} \mathrm{N}$ to $40^{\circ} \mathrm{S}$, excluding $25^{\circ} \mathrm{N}$ in the Indian Ocean [2]. ALBstock in the Indian Ocean has been primarily exploited by Taiwan, Japan, and Korea in the last five decades. Large-scale longline equipment is the main ALB fishing gear used in the Indian Ocean [3]. Most studies of this species have concerned stock discrimination, production models, and age determination, whereas studies on its distribution and how this distribution is influenced by various environmental factors have been limited, considering the fishing history of ALB tuna. The southern Indian Ocean was the targeted area in the present study. The global distribution of ALB is highly regulated by different environmental factors. Fishermen seek specific water masses when

Received 8 September 2020; revised 13 November 2020; accepted 4 December 2020.

Available online 27 December 2021

* Corresponding author. Department of Environmental Biology and Fisheries Science, National Taiwan Ocean University, Keelung, Taiwan, ROC.

E-mail addresses: mondalsandipan31@gmail.com (S. Mondal), yclan@mail.tfrin.gov.tw (Y-C. Lan), malee@ntou.edu.tw (M-A. Lee), live723@mail.ntou.edu.tw (Y-C. Wang), bambangsemedi@ub.ac.id (B. Semedi). 
targeting any species of tuna. ALB tuna catches are closely spatially related to sea surface temperature (SST) $[4,5]$ and chlorophyll [6-8] in the Ocean. Despite the southern Indian Ocean being a favorable place for ALB habitat, information regarding southern Indian Ocean oceanographic conditions is insufficient, which hinders the study of ALB tuna habitats [9]. This problem was overcome with the advent of remote sensing data. In 1981, the advanced very-high-resolution radiometer and the Nimbus-7 coastal zone color scanner were first used to evaluate the spatial distribution of ALB tuna catches in the eastern Pacific Ocean [6]. Satellite remote sensing has subsequently been widely applied to fisheries oceanography, fisheries management, and operational fisheries oceanography using the SST, thermal front, and phytoplankton pigment concentration of near-surface waters [6,8-11]. Improvement in remote sensing and geographic information systems has enabled researchers to overcome the barriers presented by the temporal and spatial scales. Understanding the distribution patterns of ALB and the effect of environmental factors in the Indian Ocean is paramount to fostering sustainable exploitation and management. Therefore, we explored the spatial and temporal distribution ofALB tuna by using remote sensing environmental variables. We used sea surface data from the southern Indian Ocean, including satellite images and fishery data collected by vessels, to comprehensively clarify the environmental preferences of ALB tuna in the Indian Ocean. These findings can improve our understanding of the dynamics of ALB tuna and benefit sustainable fishing in the Indian Ocean (Fig. 1).

\section{Materials and methods}

\subsection{Remote sensing data}

Seven types of satellite-derived and model-simulated data were used in this study: (a) SST, (b) sea surface salinity (SSS), (c) east-west direction current $(\mathrm{U}),(\mathrm{d})$ north-south direction current $(\mathrm{U}),(\mathrm{e})$ sea surface height (SSH), (f) mixed layer depth (MLD), and (g) sea surface chlorophyll-a

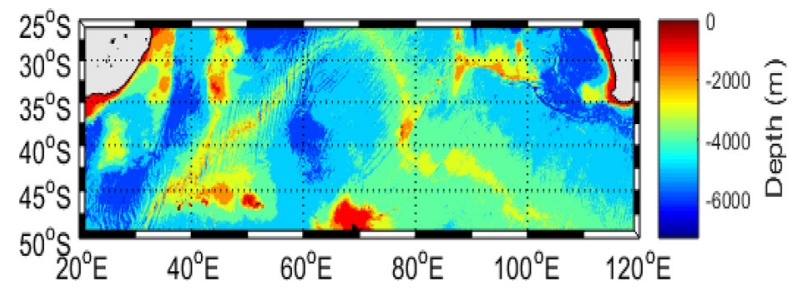

Fig. 1. Bathymetry of the southern Indian Ocean.
Table 1. Sources of the multi-satellite and satellite altimetry data applied in the model

\begin{tabular}{llll}
\hline Data & Unit & Source & Spatial Resolution \\
\hline SST & ${ }^{\circ} \mathrm{C}$ & ERDDAP & $1^{\circ} \times 1^{\circ}$ \\
SSC & $\mathrm{mg} \mathrm{m}^{-3}$ & ERDDAP & $1^{\circ} \times 1^{\circ}$ \\
SSS & $\mathrm{psu}$ & MOVE-MRI & $10 \mathrm{~km} \times 10 \mathrm{~km}$ \\
MLD & $\mathrm{m}$ & HYCOM & $1 / 12^{\circ} \times 1 / 12^{\circ}$ \\
EKE & $\mathrm{m}^{2} \mathrm{~s}^{-2}$ & AVISO & $25 \mathrm{~km} \times 25 \mathrm{~km}$ \\
SSH & $\mathrm{cm}$ & AVISO & $25 \mathrm{~km} \times 25 \mathrm{~km}$ \\
\hline
\end{tabular}

concentration as indicator of sea color (SSC). U and $\mathrm{V}$ were used to calculate eddy kinetic energy (EKE). Data were collected from $20^{\circ} \mathrm{E}$ to $120^{\circ} \mathrm{E}$ and $25^{\circ} \mathrm{S}$ to $50^{\circ} \mathrm{S}$ because Nikolic et al. (2014) [12] reported that this location is the feeding ground of ALB tuna during March to August. The sources of the satellite-derived data are listed in Table 1.

EKE was calculated as EKE $=0.5\left(\mathrm{U}^{2}+\mathrm{V}^{2}\right)$ before being used in the generalized additive model (GAM) analysis. Previous studied showed SST, SSC, SSS, MLD, SSH, EKE and SSH are very important factors in terms of describing the albacore tuna distribution. SST and SSC (for feeding) were described as important factors in previous studies while small changes in SSS effects the albacore tuna distribution. As albacore tuna is deep diver, MLD and SSH are important. EKE became also one of the important parameter as albacore tuna is a highly migratory species and eddy can provide feeding opportunities. Based on these conclusions found in previous studies authors took current 6 parameters for the analysis (Comment 2).

\subsection{ALB fishery data}

Catch and effort data were compiled from a logbook of Taiwanese long-liners ( $>100$ tonnages) in the southern Indian Ocean at $25^{\circ} S-50^{\circ} S$ and $20^{\circ} \mathrm{E}-120^{\circ} \mathrm{E}$ provided by the Overseas Fisheries Development Council of Taiwan. Catch and effort data from March-August 2009 to 2014 were collected. The data like the number of hooks, fishing time, area, catch, and fish size (fork length in $\mathrm{cm}$ ) were collected. Data were geographically referenced and averaged to obtain monthly means. The nominal catches per unit effort (CPUE) was calculated as the number of individuals captured by 1000 hooks (No. of catches $/ 10^{3}$ hooks). Data prediction of ALB tuna abundance was also performed using the logbook.

$C P U E_{i j k}=\sum C_{i j k} / \sum E_{i j k}$

where CPUE $\mathrm{ijk}_{\mathrm{i}}$ is the nominal CPUE (individuals/ 1000 hooks), $\sum C_{i j k}$ and $\sum E_{i j k}$ are the total catch and 
fishing effort (1000 hooks) in the $1^{\circ} \times 1^{\circ}$ grid, respectively, and $i, j$, and $k$ represent the month, longitude, and latitude, respectively.

\subsection{Standardization of nominal catch per unit effort}

Nominal CPUE values were suggested as an unbiased estimation index of abundance to correct for factors that may affect time-series analysis and habitat model development [9]. In general, time (year, month), space (longitude, latitude), and interactions were considered the primary factors $[13,14]$ for changes in the nominal CPUE. The model of standardized nominal CPUE was developed using R (version 2.15.0) software developed by Rstudio, PBC enterprise as follows:

$\log ($ CPUE $+c)=\mu+y+m+$ lat + lon + Inter $+\varepsilon$

Where $\varepsilon=$ error, $\mathrm{c}=$ constant given the value of $10 \%$ of the mean CPUE, $\mu=$ intercept, $y=$ effect of years (2009-2014), $\mathrm{m}=$ effect of months (March-August), lon $=$ effect of longitude, lat $=$ effect of latitude, and Inter $=$ interaction terms.

\subsection{Time-series analysis}

Time-series analysis is one of the most valuable tools for investigating the long-term fluctuations in standardized nominal CPUE and the relationship between standardized nominal CPUE and environmental variables. In the present study, a time-series analysis was performed to examine the catch rates in different months and determine the effect of various environmental factors on the catch rates from 2009 to 2014. To clarify the relationship between the CPUE and different environmental factors, a two-tailed Pearson correlation analysis was performed using SPSS (version 22.0).

\subsection{Development of an ALB tuna habitat model}

A potential feeding habitats model of ALB tuna in the southern Indian Ocean was developed using GAMs. The model was constructed using the mgcv package of $R$ software (version 2.15.0) [15]. In this model, environmental factors such as SST, SSS, SSC, SSH, MLD, and EKE were set as the predictor variables and the standardized CPUE value was the response variable. A maximum of six variables (SST, SSS, SSC, SSH, MLD, and EKE) was used to construct the functions in GAM. SST has frequently been used to relate the oceanic environment to tuna distribution [11]. Therefore, we considered SST the primary variable for identifying the habitat for ALB tuna, and different combinations of $2-5$ variables were used as habitat data.

The GAM can be written as follows:

$$
\begin{aligned}
\log \left(\operatorname{CPUE}_{\mathrm{s}}+\mathrm{c}\right)= & \mathrm{a}_{0}+\mathrm{s}_{1}\left(\mathrm{x}_{1 \mathrm{i}}\right)+\mathrm{s}_{2}\left(\mathrm{x}_{2 \mathrm{i}}\right)+\mathrm{s}_{3} \\
& \left(\mathrm{x}_{3 \mathrm{i}}\right)+\ldots \mathrm{s}_{\mathrm{n}}\left(\mathrm{x}_{\mathrm{ni}}\right)
\end{aligned}
$$

where CPUE $_{s}$ is the standardized CPUE of the longline catch data, $s_{n}$ is a smoothing function of each model covariate, and $x_{n}$ [15] and $a_{0}$ are the model constants. Furthermore, 0.1 fish per $10^{3}$ hooks were added to the CPUE $\mathrm{S}_{\mathrm{s}}$ values (c) to account for the zero catch values in the data.

A total of six variables and 11 models were evaluated. The lowest Akaike information criterion (AIC) was used to select variables for further analysis. Estimation of ALB tuna relative density in relation to SST, SSS, SSC, SSH, MLD, and EKE conditions was then performed across the southern Indian Ocean using selected GAMs. The GAMs were then used to perform ALB abundance predictions and validations from March to August. The predictions were assessed using the normal distribution based on quantile-quantile $(\mathrm{Q}-\mathrm{Q})$ plots on R-studio software.

\section{Results}

\subsection{Monthly changes in the environmental conditions of the feeding ground}

The spatial variations of different environmental factors during the study period were examined. The southern area of the southern Indian Ocean $\left(25^{\circ} S-30^{\circ} \mathrm{S}\right)$ was warmer throughout the study period. The average temperature range (Fig. 2) of this area was $18.5-28{ }^{\circ} \mathrm{C}$. The area near $25^{\circ} \mathrm{S}$ and between $35^{\circ} \mathrm{E}$ and $50^{\circ} \mathrm{E}$ had an average SST of $>23{ }^{\circ} \mathrm{C}$. The area between $40^{\circ} \mathrm{S}$ and $50^{\circ} \mathrm{S}$ was colder than other areas throughout the study period. However, the colder region extended northward from April and reached $25^{\circ} \mathrm{S}$ from July to August. During that time, the SST of the area was $17.5-19{ }^{\circ} \mathrm{C}$. The areas with $17.5-18.5{ }^{\circ} \mathrm{C}$ SST exhibited the highest abundance of ALB tuna from March to August. Higher salinity (Fig. 3) was observed in the area between $25^{\circ} \mathrm{S}$ and $45^{\circ} \mathrm{S}$. The average SSS of this area was $>34.5$ psu throughout the study period. Lower SSS was observed in the northern part of the southern Indian Ocean, ranging from 33 to $34 \mathrm{psu}$. The areas with an SSS of more than $35 \mathrm{psu}$ and less than $34 \mathrm{psu}$ had a lower abundance of ALB tuna. The SSC of the study area ranged from 0.11 to $0.55 \mathrm{mg} / \mathrm{m}^{3}$ (Fig. 4), and the lowest SSC (between 0.04 and $0.1 \mathrm{mg} / \mathrm{m}^{3}$ ) were 

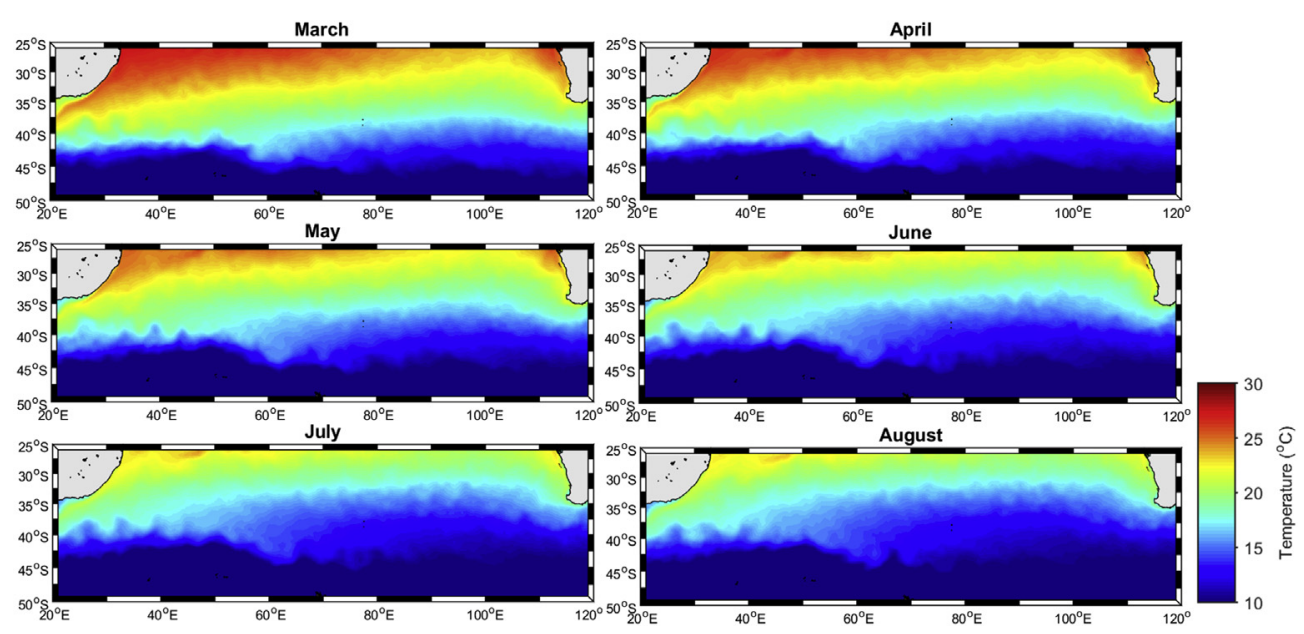

Fig. 2. Mean monthly SST from March to August 2009-2014.
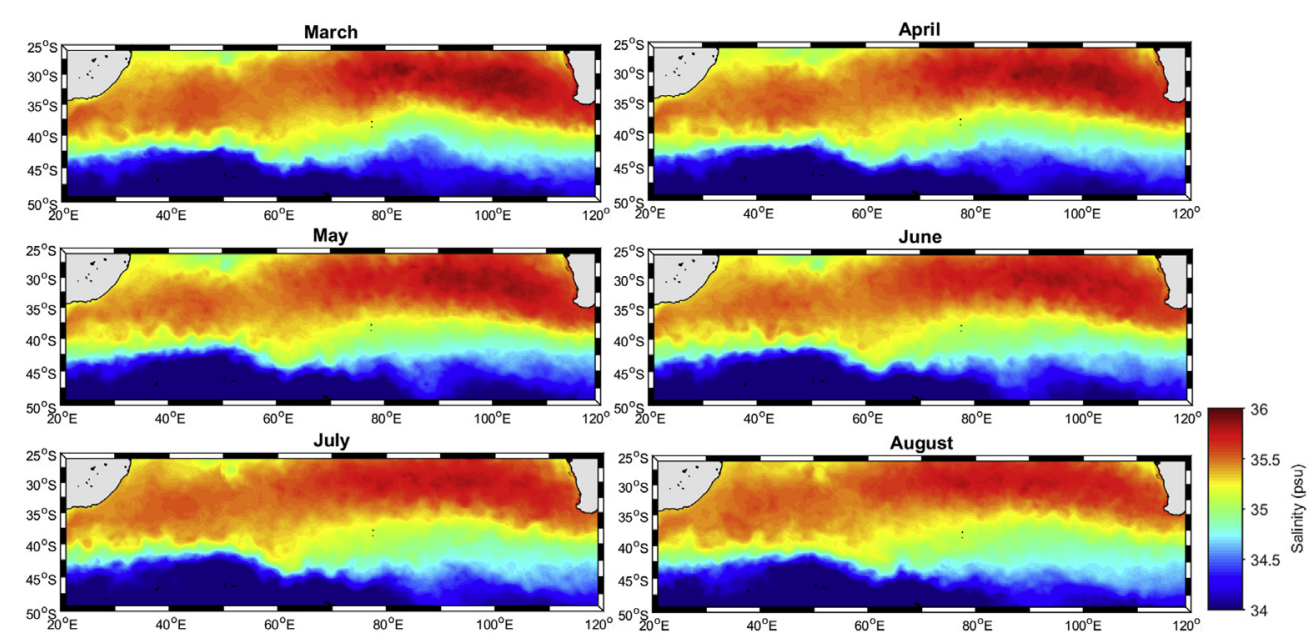

Fig. 3. Mean monthly SSS from March to August 2009-2014.

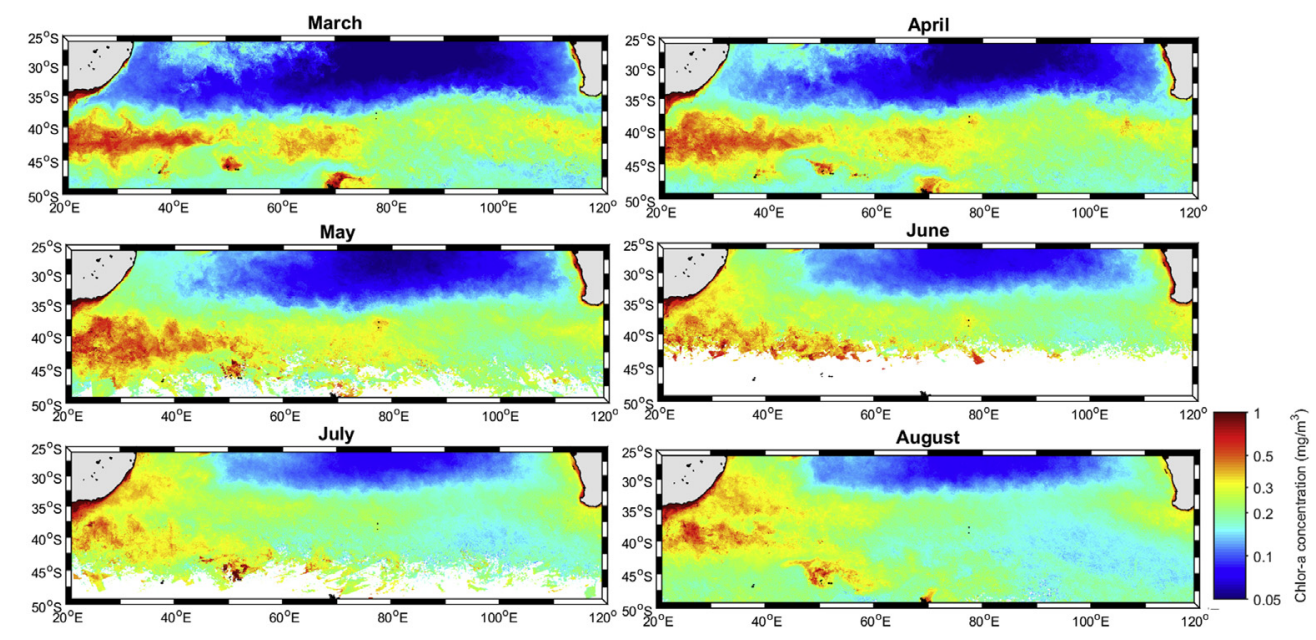

Fig. 4. Mean monthly SSC from March to August 2009-2014. 

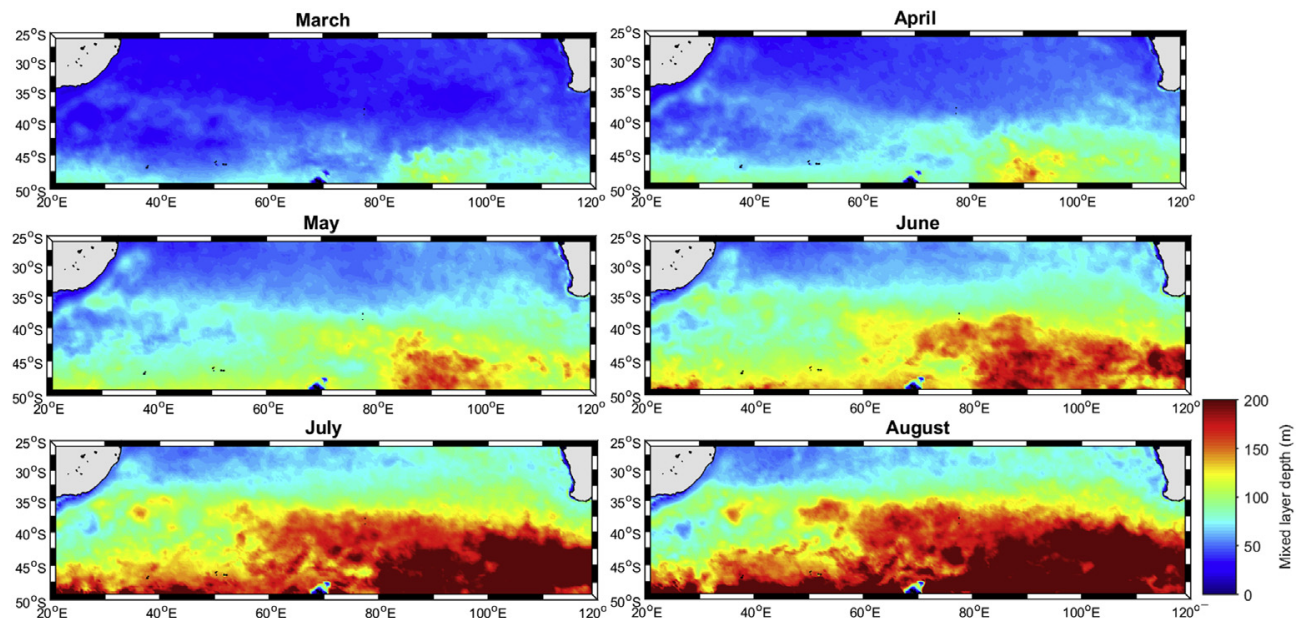

Fig. 5. Mean monthly MLD from March to August 2009-2014.
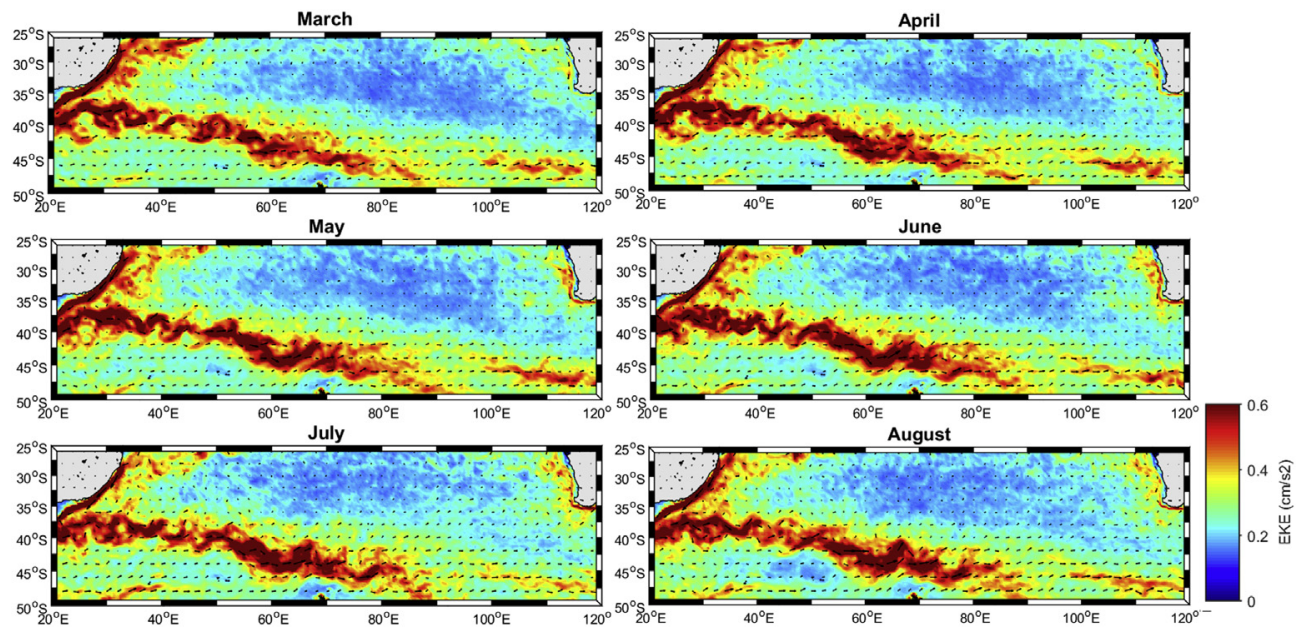

Fig. 6. Mean monthly EKE from March to August 2009-2014.
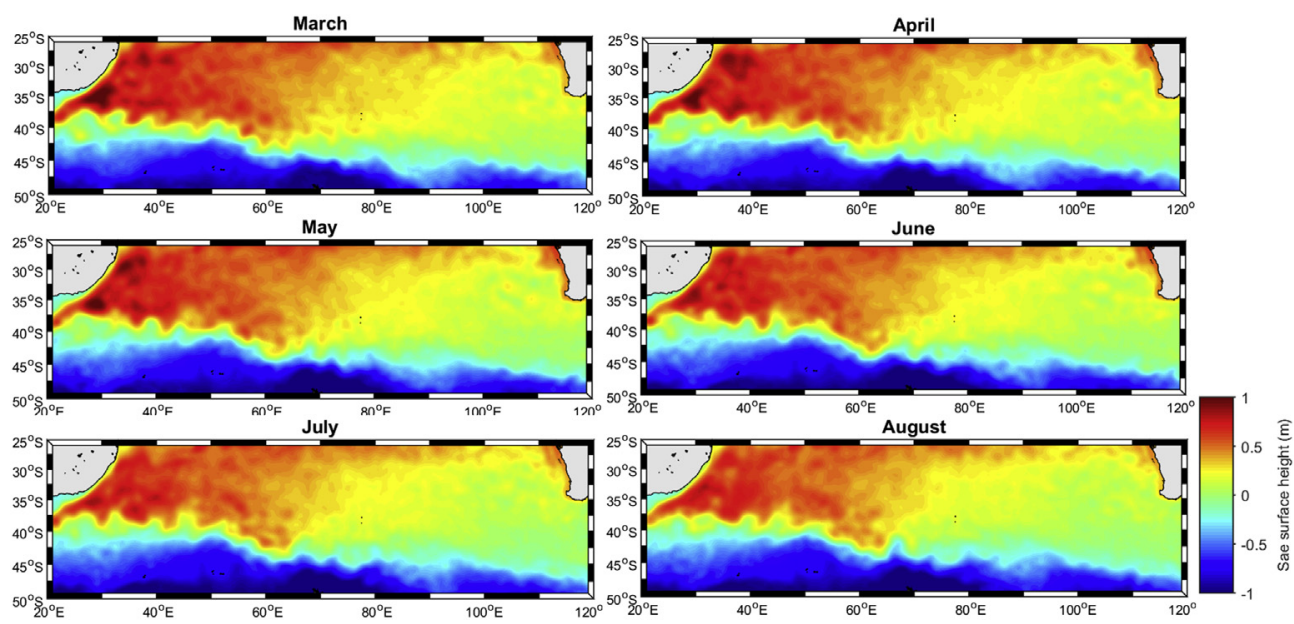

Fig. 7. Mean monthly SSH from March to August 2009-2014. 

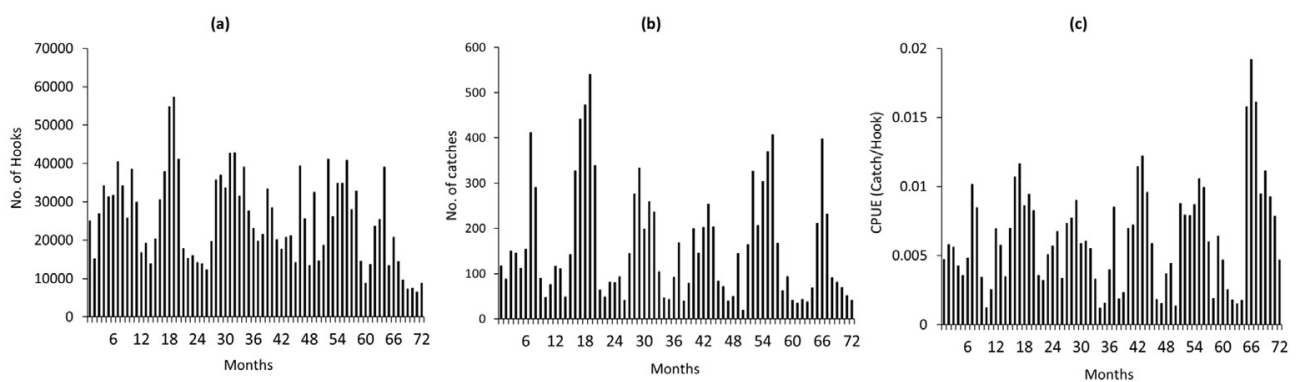

Fig. 8. Diagram of the (a) fishing effort, (b) number of albacore catches, and (c) all monthly $\left(1-72^{\text {nd }}\right.$ ) nominal CPUE of albacore from 2009 to 2014 (Comment 1).
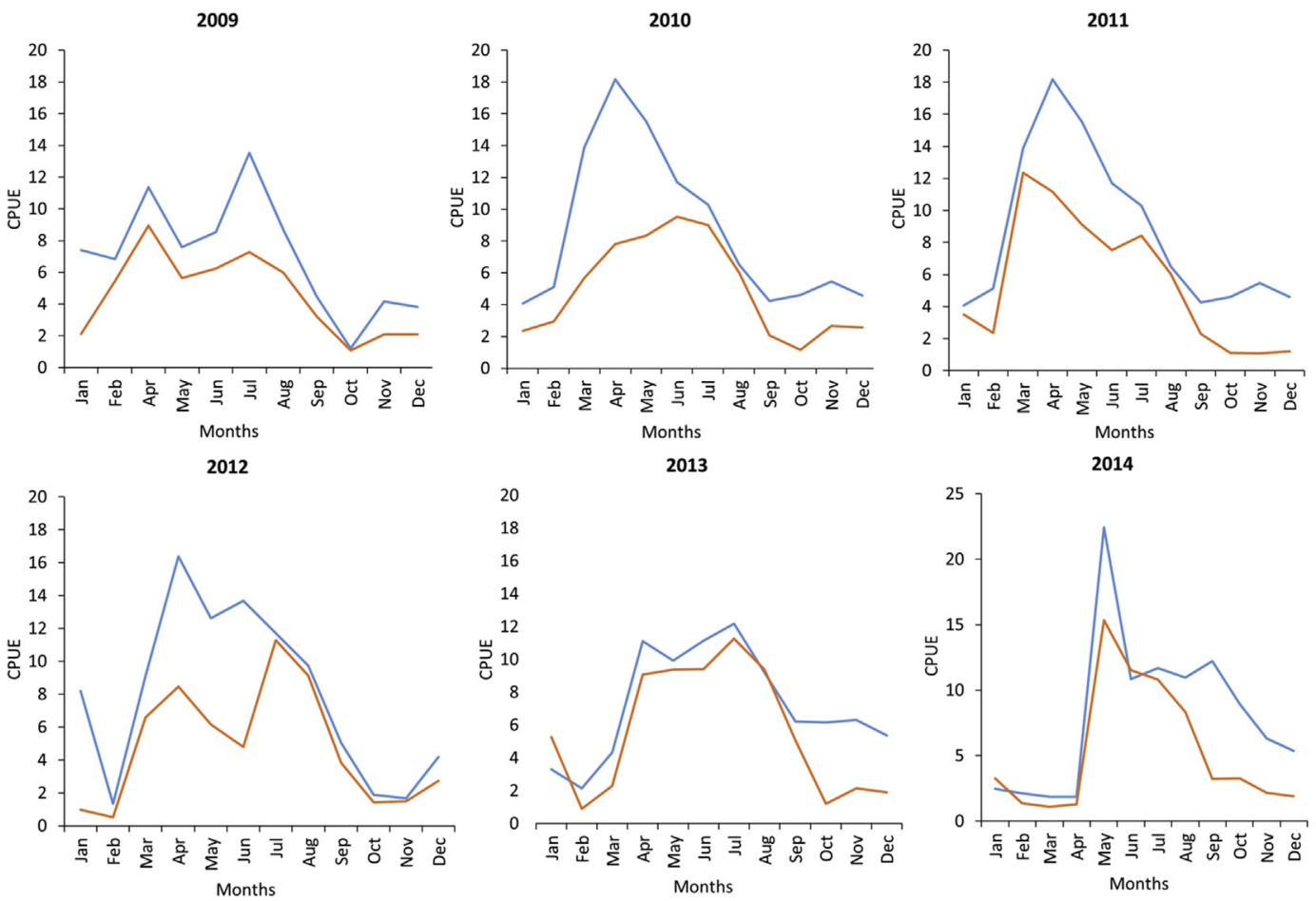

\section{Monthly Mean}

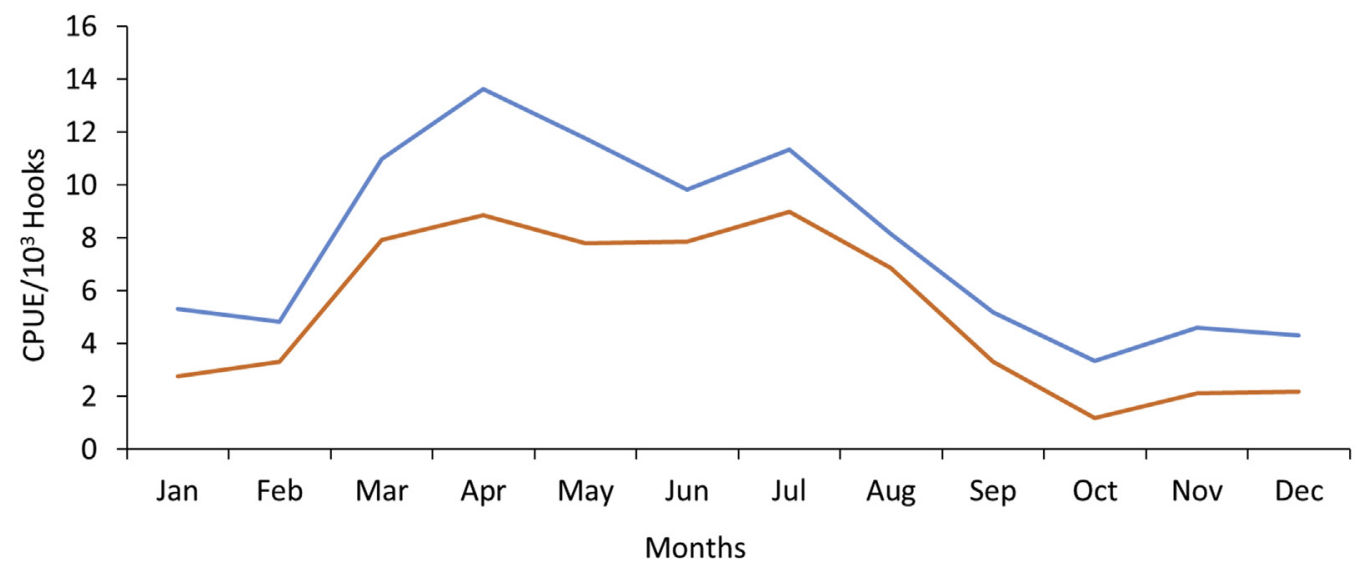

-Series1 -Series2

Fig. 9. Graph of the nominal and standardized CPUE from 2009 to 2014 and the monthly means for 2009-2014. Series 1 and series 2 illustrate the nominal and standardized CPUE/103 hooks. 
(a)

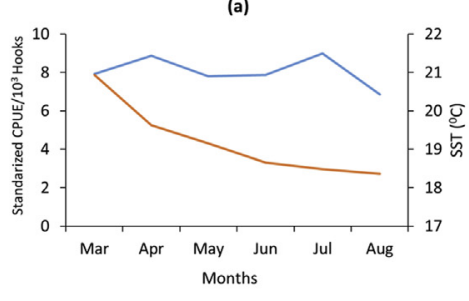

(b)

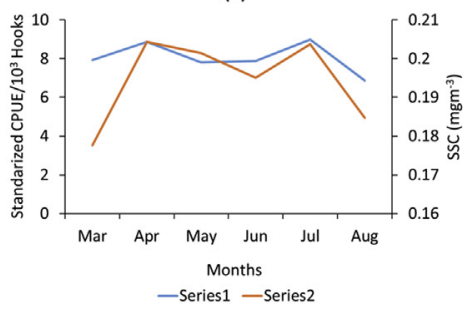

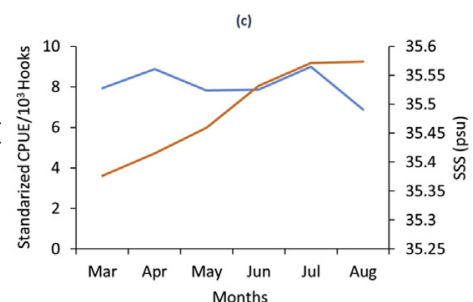

(d)

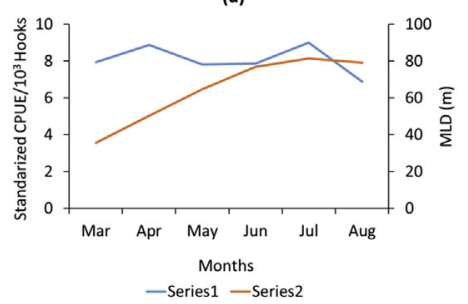

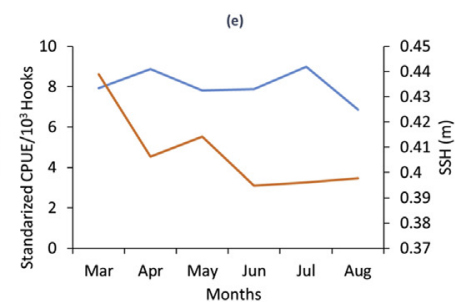

(f)

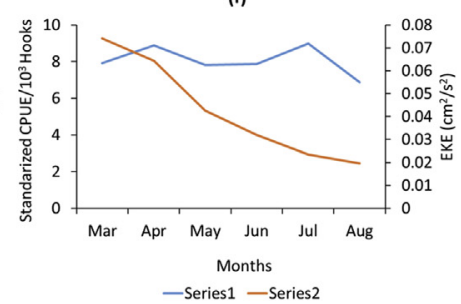

Fig. 10. Time-series analysis between the CPUE and (a) SST, (b) SSC, (c) SSS, (d) MLD, (e) SSH, and (f) EKE. Orange and Blue indicates standardized CPUE and environment value, respectively.

located at $25^{\circ} \mathrm{S}-30^{\circ} \mathrm{S}$ and $60^{\circ} \mathrm{E}-100^{\circ} \mathrm{E}$. Higher SSC was observed throughout the year in the northern part of the southern Indian Ocean $\left(35^{\circ} S-45^{\circ} S\right)$, with a range of $0.15-0.3 \mathrm{mg} / \mathrm{m}^{3}$. A notable fluctuation in SSC was observed at $45^{\circ} \mathrm{S}-50^{\circ} \mathrm{S}$ and $20^{\circ} \mathrm{E}-120^{\circ} \mathrm{E}$. In June, this area exhibited an SSC of less than $0.01 \mathrm{mg} / \mathrm{m}^{3}$. However, a southward shift of the area was observed in July, and the area, restricted to $50^{\circ} \mathrm{S}$, displayed an SSC of less than $0.01 \mathrm{mg} / \mathrm{m}^{3}$. Areas with a $0.1-0.2 \mathrm{mg} / \mathrm{m}^{3}$ SSC displayed an abundance of ALB, and an SSC range of $0.1-0.15 \mathrm{mg} / \mathrm{m}^{3}$ was associated with the highest $\mathrm{CPUE}_{\mathrm{s}}$ values. The areas at $40^{\circ} \mathrm{S}-50^{\circ} \mathrm{S}$ and $80^{\circ} \mathrm{E}-100^{\circ} \mathrm{E}$ had the highest MLD (Fig. 5) in the southern Indian Ocean in May. This area extended both eastward and westward in June, and the area reached up to $35^{\circ} \mathrm{S}$ toward the north, $20^{\circ} \mathrm{E}$ toward

Table 2. Results of the Pearson correlation coefficient test between standardized CPUE and different environmental variables

\begin{tabular}{lll}
\hline Environmental factors & R-values & $\mathrm{p}$ value \\
\hline SSC & 0.41 & $<0.01$ \\
SSS & -0.52 & $<0.01$ \\
SST & 0.62 & $<0.01$ \\
MLD & -0.62 & $<0.01$ \\
SSH & 0.12 & $<0.01$ \\
EKE & 0.25 & $<0.01$ \\
\hline
\end{tabular}
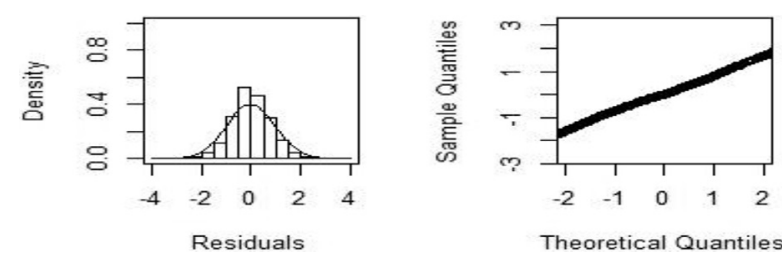

Fig. 11. Residual distributions and $Q-Q$ plots for diagnostic analysis of the final GAMs with prediction variables (presented in Table 3) according to fishery and remote sensing data. the west, and $120^{\circ} \mathrm{E}$ toward the east from July to August. A higher EKE (Fig. 6) was observed at $35^{\circ} \mathrm{S}-45^{\circ} \mathrm{S}$ and $20^{\circ} \mathrm{E}-80^{\circ} \mathrm{E}$. The average EKE of this area throughout the year was between 0.03 and $0.26 \mathrm{~cm}^{2} / \mathrm{s}^{2}$. Furthermore, the SSH was higher in areas located at $25^{\circ} \mathrm{S}-40^{\circ} \mathrm{S}$ and $20^{\circ} \mathrm{E}-70^{\circ} \mathrm{E}$ and lower in areas at $45^{\circ} \mathrm{S}-50^{\circ} \mathrm{S}$ at 0 and $0.04 \mathrm{~m}$, respectively (Fig. 7).

\subsection{Standardization of nominal CPUE data}

Figure 8 showed the fishing effort, albacore catch and nominal CPUE every month from 2009 to 2014 (comment 1) The highest and lowest CPUE values during the study period were observed in April (13.56 fish $/ 10^{3}$ hooks) and August (7.86 fish $/ 10^{3}$ hooks), respectively.

Data standardization ensures that data is internally consistent and that each data type has the same content and format. Standardized values are useful for tracking data that are not easy. to compare otherwise. Because of the use of six environmental factors, CPUE values above or below the normal value could have been obtained in certain parts of the study area.

Figure 9 illustrates the difference in nominal and standardized CPUE for each month from 2009 to 2014 and the monthly means of nominal and standardized CPUE for 2009-2014.

In 2014, Nikolic et al. [12] reported that the present study area is the feeding ground of ALB tuna from March to August in the Indian Ocean, and the results of the standardized CPUE and nominal CPUE further indicated higher values from March to August. Therefore, March to August was selected as the study period. 
Table 3. Residual deviance and AIC of the CPUE values of high-spatial-resolution longline catch data explained in GAMs with sequentially added variables (first to last)

\begin{tabular}{llll}
\hline GAMS & Deviance explained (\%) & AIC & p value \\
\hline Model-1 (SST) & 18.2 & 20019.99 & $<0.01$ \\
Model-2 (SST + SSS) & 31.3 & 18850.24 & $<0.01$ \\
Model-3 (SST + SSS + SSC) & 40.7 & 18714.76 \\
Model-4 (SST + SSS + SSC + MLD) & 44.9 & 18706.51 & $<0.01$ \\
Model-5 (SST + SSS + SSC + MLD + EKE) & 47.5 & 18683.01 & $<0.01$ \\
Model-6 (SST + SSS + SSC + MLD + EKE + SSH) & 47.6 & 18678.37 & $<0.01$ \\
Model-7(SSS) & 16.5 & 20808.37 \\
Model-8(SSC) & 13.4 & 20778.01 & $<0.01$ \\
Model-9 (MLD) & 11.4 & 20756.48 & $<0.01$ \\
Model-10 (EKE) & 4.17 & 21227.23 & $<0.01$ \\
Model-11(SSH) & 1.46 & 21302.04 & $<0.01$ \\
\hline
\end{tabular}
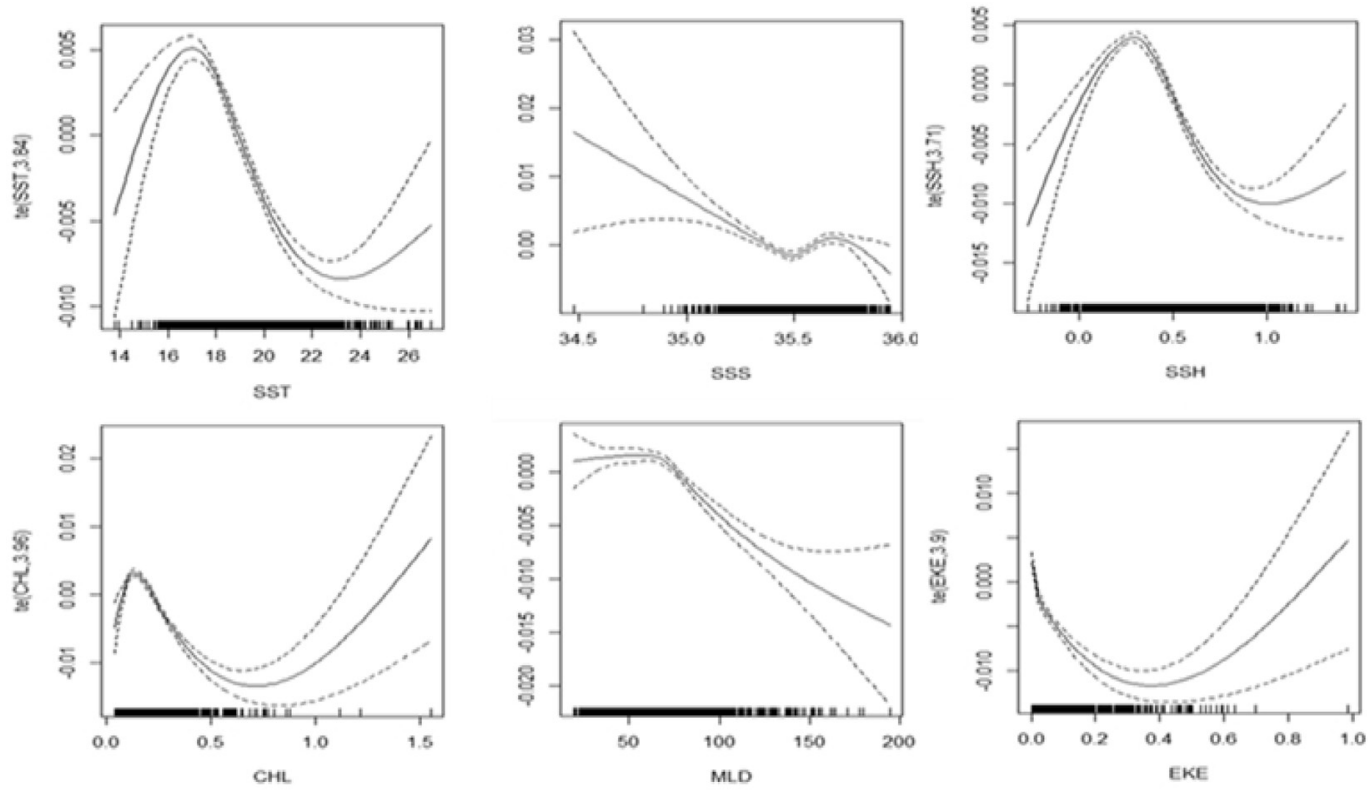

Fig. 12. Modeled effects of SST, SSC, SSS, MLD, EKE, and SSH on CPUE values. Solid lines represent the fitted GAM function, and black-dotted lines indicate the $95 \%$ confidence intervals. The relative densities of the data points are indicated by the rug plot on the $x$-axis.

\subsection{Time-series analysis}

A continuous increasing-decreasing trend in the CPUE values was observed during the study period. The relationship between monthly mean CPUE and the monthly mean values of the environmental factors is illustrated in Fig. 10.

This variability between CPUE and environmental factors was explained by the $R$ values of the twotailed Pearson correlation (Table 2). The Pearson correlation coefficient test revealed a significant correlation between all the environmental factors and the CPUE (Table 2); SST, SSC, SSH, and EKE exhibited positive correlations with CPUE, whereas SSS and MLD exhibited negative correlations with CPUE. SST showed the highest positive relation with the SST with a $R$ value of 0.62 followed by SSC $(R=0.41)$ and EKE $(R=0.25)$. This implied SST as the dominant factor in the present study followed by SSC and EKE. These results implied that increase in the values of these factors are directly. related to the increase of abundance. MLD and SSS showed R value of -0.62 and -0.52 and concluded that decrease in these values caused increase in abundance (comment 2)

\subsection{GAM analysis}

GAM analysis predictions were confirmed using the normal distribution based on $\mathrm{Q}-\mathrm{Q}$ plots; the log-spaced residuals of all the environmental factors were independent and appeared to be normally distributed (Fig. 11).

All the environmental variables included in the GAM selection process were significant $(p<0.01)$. The cumulative deviance with the lowest AIC value 


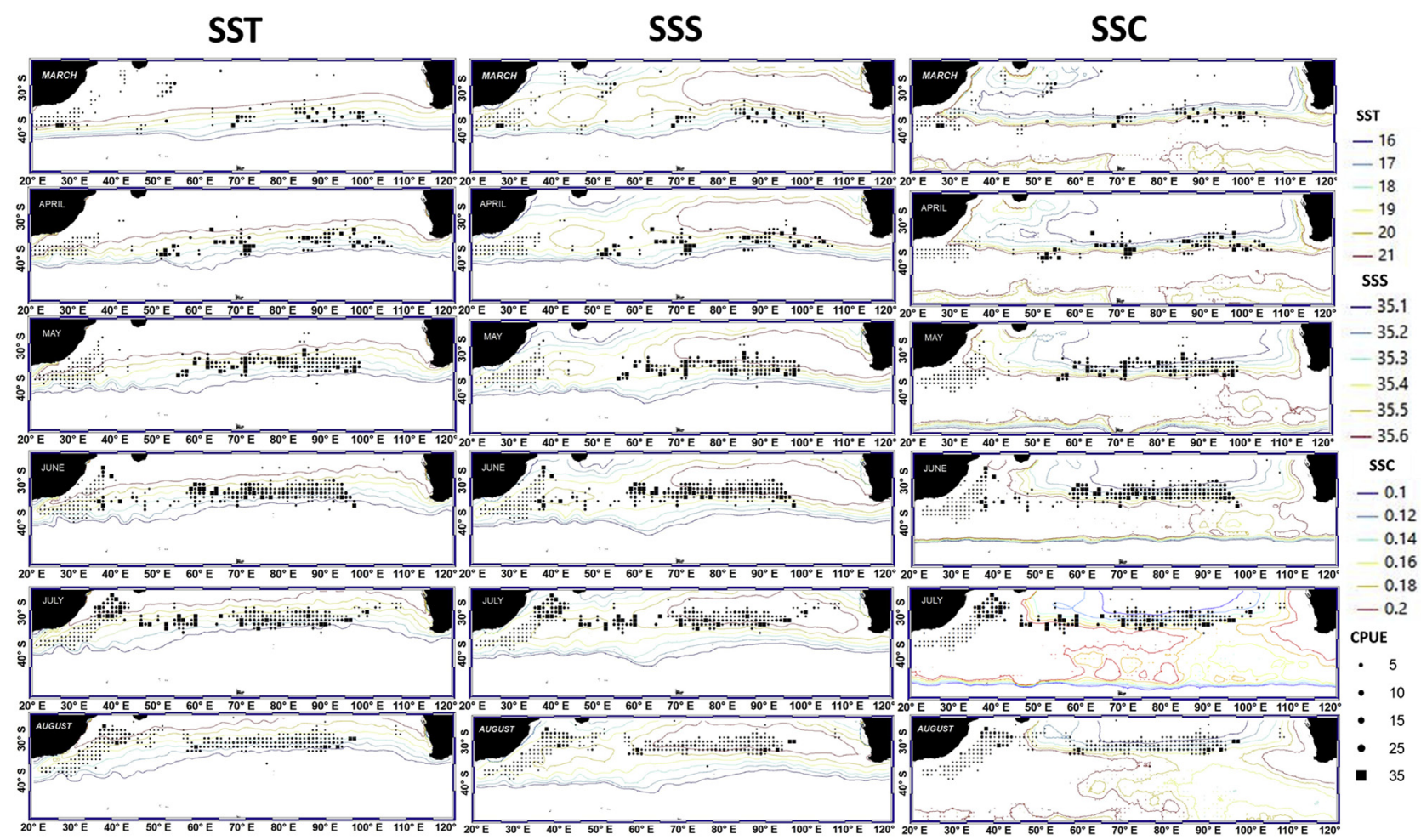

Fig. 13. Representation of the standardized mean monthly CPUE from March to August in 2009-2014. Standardized CPUE values with $16^{\circ} \mathrm{C}, 17^{\circ} \mathrm{C}$, $18^{\circ} \mathrm{C}, 19^{\circ} \mathrm{C}, 20^{\circ} \mathrm{C}$, and $21^{\circ} \mathrm{C}$ isotherm lines; $35.1 \mathrm{psu}, 35.2 \mathrm{psu}, 35.3 \mathrm{psu}, 35.4 \mathrm{psu}, 35.5 \mathrm{psu}$, and $35.6 \mathrm{psu}$ and $0.15 \mathrm{mg} / \mathrm{m}^{3}, 0.1 \mathrm{mg} / \mathrm{m}^{3}, 0.12 \mathrm{mg} / \mathrm{m}^{3}$, $0.14 \mathrm{mg} / \mathrm{m}^{3}, 0.16 \mathrm{mg} / \mathrm{m}^{3}, 0.18 \mathrm{mg} / \mathrm{m}^{3}$, and $0.20 \mathrm{mg} / \mathrm{m}^{3}$ isopleth lines from March to August in 2009-2014].

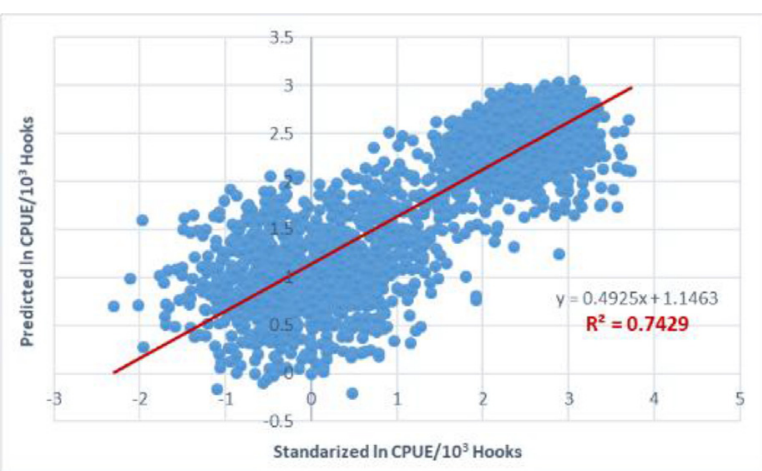

Fig. 14. Scatter plot illustrating the relationship between standardized and predicted CPUE.

explained by the Model-6 GAM was 47.6 (Table 3). The relationships between different models and the CPUE values were examined using R-studio software and are displayed in Fig. 12. SST had the largest effect of all the environmental factors studied, followed by SSS and SSC. These three factors explained over $40 \%$ of the total deviance. Table 3 showed SST with most deviance explained $(18.2 \%)$ supporting the result of Table 2. Second and third highest deviance explained were by SSS and SSC $16.5 \%$ and $13.4 \%$ respectively (comment 3)

\subsection{Spatial distribution of standardized CPUE in relation to crucial environmental factors derived from the GAM analysis}

The spatial distributions of standardized CPUE values during the study period are illustrated in Fig. 13. From March to August, higher CPUE values were observed in the areas at $30^{\circ} S-40^{\circ} S$ and $60^{\circ} \mathrm{E}-100^{\circ} \mathrm{E}$. The CPUE was highly concentrated around $35^{\circ} \mathrm{S}$. After March, the abundance started shifting northward, and higher CPUE values were observed near $30^{\circ} \mathrm{S}$ by July-August. During July and August, the south end of the Madagascar coast also exhibited high CPUE values. Three environmental factors with higher AIC values were also included in the standardized CPUE values. Several factors for SST, SSS, and SSC were included to further clarify the spatial distribution of standardized CPUE in relation to critical environmental factors: $16^{\circ} \mathrm{C}, 17{ }^{\circ} \mathrm{C}, 18{ }^{\circ} \mathrm{C}, 19^{\circ} \mathrm{C}, 20^{\circ} \mathrm{C}$, and $21^{\circ} \mathrm{C}$ isotherm lines; $35.1 \mathrm{psu}, 35.2 \mathrm{psu}, 35.3 \mathrm{psu}, 35.4 \mathrm{psu}$, $35.5 \mathrm{psu}$, and $35.6 \mathrm{psu}$ isopleth lines; and $0.15 \mathrm{mg} /$ 


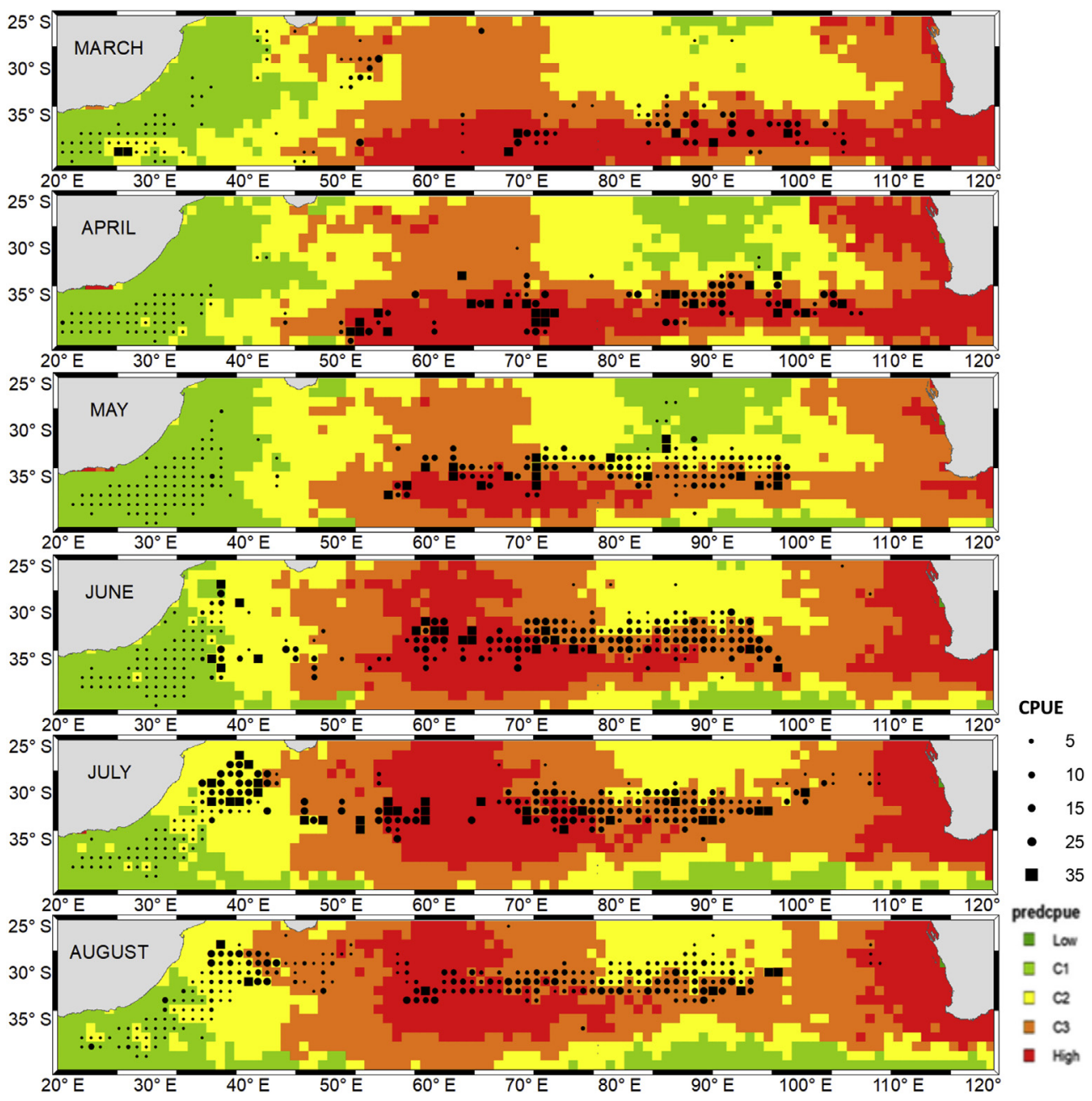

Fig. 15. The mean monthly prediction of feeding habitat zones and their relationship.

$\mathrm{m}^{3}, 0.1 \mathrm{mg} / \mathrm{m}^{3}, 0.12 \mathrm{mg} / \mathrm{m}^{3}, 0.14 \mathrm{mg} / \mathrm{m}^{3}, 0.16 \mathrm{mg} / \mathrm{m}^{3}$, $0.18 \mathrm{mg} / \mathrm{m}^{3}$, and $0.20 \mathrm{mg} / \mathrm{m}^{3}$ isopleth lines. Figure 13 illustrates the relationship between these values and a higher abundance of ALB tuna during the study period. The spatial distribution of standardized CPUE values (Fig. 13) also indicates higher values near the isotherm and isopleth lines.

\subsection{Model validation and the development of an $A L B$ tuna feeding habitat zone and its relation to} standardized CPUE

Model-6, which displayed the lowest AIC value, was further used to predict the CPUE (mean) from March to August from 2009 to 2014. The relation between the standardized and predicted CPUE for 2009-2014 had previously been statistically described to validate Model-6. Statistical analysis (Fig. 14) revealed that the regression (R) value of the standardized and predicted CPUE was 0.861 . Model-6 was then used to identify the feeding habitat zones and potential fishing zones (Fig. 15). A Potential Fishing Zone (PFZ) is a proxy to potential shoals of fish aggregation will benefit the fishing community to reduce the time and effort spent in searching the shoals of fish, thus improving the profitability and hence, the socioeconomic status (comment 3) The maximum predicted CPUE values were observed at $35^{\circ} \mathrm{S}-40^{\circ} \mathrm{S}$ and $25^{\circ} \mathrm{S}-35^{\circ} \mathrm{S}$ from March to May and June to August, respectively.

\section{Discussion}

ALB tuna is a typical temperate and highly migratory tuna species (similar to the Bluefin and southern Bluefin species). ALB tuna engages in extensive seasonal migrations (related to both feeding and spawning) at all ages. Furthermore, this species exhibits homing behavior (i.e., adults return to the area where they were born) within its small spawning strata [16]. 
The results of this study indicated that the temporal and spatial distributions of ALB tuna longline catches were affected by climatic factors in the southern Indian Ocean. SST was the most accurate predictor of CPUE in ALB longline fishing, which indicates a strong relationship between SST and CPUE. On an ocean scale, SST not only represents temperature but also corresponds to latitude [17]. Most studies on the Pacific Ocean have reported lower and upper limits of suitable SSTs for ALB tuna of $14{ }^{\circ} \mathrm{C}$ and $23{ }^{\circ} \mathrm{C}$, respectively, with high CPUE values occurring between $14{ }^{\circ} \mathrm{C}$ and $21^{\circ} \mathrm{C}$ [18]. However, different findings have been obtained for the Indian Ocean, where areas with an SST of over $24{ }^{\circ} \mathrm{C}$ [19] have been reported. The present study revealed an abundance of ALB tuna in areas with an SST range of $16-21{ }^{\circ} \mathrm{C}$, with 18-19 ${ }^{\circ} \mathrm{C}$ displaying the highest CPUE. The most centralized was at $18.5{ }^{\circ} \mathrm{C}$ in almost all the study months. Lee et al. [20] concluded that SST $\left(17-21{ }^{\circ} \mathrm{C}\right)$ explained the habitat pattern of ALB tuna predominantly in the southern Indian Ocean and reported that SST was the primary factor influencing the geographic distribution of ALB tuna. Zainuddin et al. [10] reported that the highest CPUE values in the northwestern North Pacific Ocean during November were in areas where the SST ranged from 18.5 to $20.5{ }^{\circ} \mathrm{C}$. They further reported that $20^{\circ} \mathrm{C}$ was the centralized CPUE SST. Lan et al. [9] described areas with an SST range of 16-18.5 ${ }^{\circ} \mathrm{C}$ as the high CPUE zone in the southern Indian Ocean because $95 \%$ of high CPUE values were recorded in areas of $16-18.5{ }^{\circ} \mathrm{C}$ SST during June to September. Wang et al. [1] reported a strong association between CPUE and $20-27{ }^{\circ} \mathrm{C}$ SST. Chen et al. [17] determined that ALB tuna catches in the entire Indian ocean cover a wider range of SST than do those in other oceans. Studies have reported that $15-21{ }^{\circ} \mathrm{C} \mathrm{SST}$ is associated with higher CPUE, concluding that the equatorial area is unsuitable for ALB tuna fishing because it has a higher SST throughout the year and ALB tuna is primarily the bycatch in this area. The ALB tuna SST preference has further been reported to vary depending on the stage of development, with $18.9{ }^{\circ} \mathrm{C}, 19.1{ }^{\circ} \mathrm{C}$, and $24.9{ }^{\circ} \mathrm{C}$ being the optimal conditions for immature, mature non-spawning, and mature spawning ALB tunas, respectively. The present study presents a general overview of ALB tuna habitat preference in the southern Indian Ocean during March to August, which was described as the ALB tuna feeding zone in the Indian Ocean by Nikolic et al. [12], possibly for both mature and immature ALB tuna. The SST results of the present study differed slightly from those of other studies, possibly because of the study location and period.

The second most influential predictor of ALB tuna distribution was SSS. The present study indicated a satisfactory abundance of ALB tuna in areas with an SSS of 35.1-35.6 psu. Wang et al. reported that an SSS of 34.5-35.5 psu was optimal for ALB tuna in the Indian Ocean [1]. Roberts [21] described a higher catch rate in subtropical water $(45.5 \%)$ with $>35.4$ psu salinity on the coast of New Zealand, followed by in a subtropical convergence zone $(45.5 \%)$ with $34.6-35.4$ psu salinity. Novianto et al. [22] demonstrated a positive and negative effect of SSS on the catch of ALB tuna with $34.3-34.47$ psu and $>34.52$, respectively, in the eastern Indian Ocean. These results differ from those of other studies because of the time period, fisheries data classification, and environmental data variables. Chen et al. [17] reported that the salinity preferences of immature and mature (spawning) ALB tuna with higher CPUE values were 35.32 and 35.01 psu salinity, respectively. Furthermore, the effect of SSS is lower on nonspawning mature ALB tuna. The results of the present study may be representative for both mature and immature ALB tuna because the location assessed was an ALB tuna feeding zone, according to Nikolic et al. [12]. Furthermore, small differences in the results compared with those of previous studies may be explained by differences in the study period and areas investigated.

Another crucial factor in the distribution of ALB tuna was SSC. SSC is believed to be a useful factor for identifying ALB tuna abundance. Studies have reported that the southern Indian Ocean is the feeding ground for ALB tuna from March to August. The present study revealed that areas with an SSC of $0.1-0.25 \mathrm{mg} / \mathrm{m}^{3}$ exhibited an abundance of ALB tuna, with the highest CPUE values observed for an SSC of $0.1-0.15 \mathrm{mg} / \mathrm{m}^{3}$. CPUE was decreased in areas with an SSC of $<0.1 \mathrm{mg} / \mathrm{m}^{3}$ or $>0.25 \mathrm{mg} / \mathrm{m}^{3}$. Wang et al. (2019) indicated that the stronger associations between the CPUE and SSC occurred when the SSC was between 0.1 and $0.2 \mathrm{mg} / \mathrm{m}^{3}$. Chen et al. [17] reported that higher SSC for the gathering of immature ALB tuna is an indicator of higher primary production. They further reported that areas with a SSC of $0.17 \mathrm{mg} / \mathrm{m}^{3}$ had higher CPUE than areas with an SSC of $0.09 \mathrm{mg} / \mathrm{m}^{3}$ in the Indian Ocean. Laurs et al. [6] revealed the role of chlorophyll in ALB tuna distribution. According to Arrizabalaga et al. [23], ALB tunas favor relatively low levels of chlorophyll $\left(0.11-0.22 \mathrm{mg} / \mathrm{m}^{3}\right)$, although the species can tolerate a wide range of chlorophyll levels. Zainuddun et al. [10] reported that $0.3 \mathrm{mg} / \mathrm{m}^{3}$ 
was optimal for the catch in the northwestern Pacific Ocean, which is slightly higher than the optimal concentration in the present study area. The present study offers a general overview of oceanic parameters for ALB tuna in the southern Indian Ocean that may include both mature and immature ALB tuna and the differences in the SSC results may be attributable to differences in the study period and location.

Other environmental factors, including MLD, SSH, and EKE, were also significantly correlated with CPUE values, but the deviance explained by these factors was lower. Studies have supported the hypothesis that adult-sized classes can occupy both shallow and deep habitats [24-26]. The MLD preferences of ALB tuna may differ depending on the region because of various factors, such as prey type and temperature. The present study indicated that a wide range of MLDs are acceptable for ALB tuna, although higher CPUE values were observed in areas with an MLD of 60-175 m. Arrizabalaga et al. [23] concluded that the MLD preference of temperate tunas is higher than in tropical tunas $(<80 \mathrm{~m})$, and in the case of ALB tuna MLD preference, may extend up to $200 \mathrm{~m}$. Williams et al. [27] used satellite archival tags and reported an MLD range of 53-173 m, which was attained by ALB tuna in the south Pacific Ocean. Childers et al. [28] explained that immature ALB tuna frequently dive to depths exceeding $200 \mathrm{~m}$ during the day and remain near the surface mixed layer at night in the North Pacific Ocean. Cosgrove et al. [29] observed ALB tuna descending up to $450 \mathrm{~m}$ in the north Atlantic, and Lee et al. [20] reported that 60-120 m MLD was optimal for ALB tuna abundance in the southern Indian Ocean. These varying results indicate that ALB tuna accept a wide range of MLDs. Large catches of ALB tuna were observed in areas with higher EKE (e.g., $0.26 \mathrm{~cm}^{2} / \mathrm{s}^{2}$ ) in the present study. Zainuddin et al. [10] similarly reported that areas with higher EKE had a greater concentration of ALB tuna throughout the year because ALB tuna is a highly migratory species. Kimura et al. [30] explained that eddies transport the prey of ALB tuna, providing them with more feeding opportunities. ALB tuna exhibited peak CPUE in areas with an SSH of $0.5 \mathrm{~m}$. Lee et al. [20] reported that an SSH of 0.4-0.6 m was suitable for high ALB tuna abundance.

The effect of environmental conditions, deduced using the GAMs, indicated that environmental variables influence the quantity of ALB tuna caught vertically. Among all the environmental factors, SST $(18.2 \%)$ explained the most variance (Table 2), followed by SSS $(16.5 \%)$ and SSC (13.4\%). These three factors accounted for over $40 \%$ of the total deviance explained. SST explained the most deviance and had the lowest AIC of all the parameters. As Daqamseh et al. [31] explained, oceanic parameters such as SST, SSS, and SSC are the primary factors determining fish aggregation during the summer and winter seasons. Figure 12 illustrates the effects of different environmental factors on CPUE, which are explained in Table 2 . The results revealed that the maximum CPUE was concentrated near $18{ }^{\circ} \mathrm{C}$ SST, 35.5 psu SSS, and $0.15 \mathrm{mg} / \mathrm{m}^{3}$ SSC. Based on these findings, predictions for 2009-2014 were performed and $16-21^{\circ} \mathrm{C}$ isotherms, $35.1-35.6 \mathrm{psu}$, and $0.1-0.15 \mathrm{mg} / \mathrm{m}^{3}$ isopleths lines were drawn to identify the exact environmental preferences of ALB tuna (Fig. 13) and explain a maximal amount of CPUE deviation (Fig. 12). Zainuddin and Saitoh (2004) [32] reported that a higher abundance of ALB tuna could be observed in waters with an SST of 18-20 ${ }^{\circ} \mathrm{C}$. Wang et al. [1] reported that an SSS of 34.5-35.5 psu was an influential factor for the ALB habitat in the Indian Ocean. According to Arrizabalaga et al. [23], ALB tuna favor relatively low levels of SSC $\left(0.11-0.22 \mathrm{mg} / \mathrm{m}^{3}\right)$. The spatial distribution of ALB tuna indicated an abundance of the species in the areas at $35^{\circ} \mathrm{S}-40^{\circ} \mathrm{S}$, at $30^{\circ} \mathrm{S}-35^{\circ} \mathrm{S}$, and near $30^{\circ} \mathrm{S}$ in March to May, June to July, and August, respectively (Fig. 13). The maximum CPUE was centralized near $30^{\circ} \mathrm{S}$. These areas had SST, SSS, and SSC ranges of $16-21{ }^{\circ} \mathrm{C}, 35.1-35.6 \mathrm{psu}$, and $0.1-0.15 \mathrm{mg} / \mathrm{m}^{3}$, respectively, throughout the study period. These results indicate that SST, SSS, and SSC are the key factors explaining the abundance of ALB tuna in certain areas during the study period. The current results accord with previous findings. Chen et al. [17] reported that $25^{\circ} S-45^{\circ} \mathrm{S}$ was an area with high CPUE and an SST of $15-21{ }^{\circ} \mathrm{C}$. They further reported that the location was a high primary production area that attracts and feeds schools of ALB tuna. Lan et al. [9] reported a higher CPUE near $30^{\circ} \mathrm{S}$ in the southern Indian Ocean from June to September, when the SST range was $16-18.5{ }^{\circ} \mathrm{C}$. Wang et al. [1] reported that an SSS of 34.5-35.5 psu was optimal for ALB tuna habitats in the Indian Ocean in the area between $20^{\circ} S$ and $40^{\circ} S$, where CPUE was the highest. Longitudinally, higher ALB tuna abundance was observed between $60^{\circ} \mathrm{E}$ and $100^{\circ} \mathrm{E}$ from March to May, $60^{\circ} \mathrm{E}-100^{\circ} \mathrm{E}$ and $35^{\circ} \mathrm{E}-40^{\circ} \mathrm{E}$ from June to July, and between $50^{\circ} \mathrm{E}$ and $55^{\circ} \mathrm{E}$ in August. Agulhas leakage causes the outflow of the Indian Ocean water to the Atlantic Ocean and vice versa [33]. A higher CPUE may be observed on the east coast of South Africa because of the migration of South Atlantic Ocean ALB tuna to the South Indian Ocean through Agulhas leakage. 
Beardsley [34] discussed interoceanic ALB tuna migration and indicated that unknown numbers of ALB tuna may migrate from the South Atlantic Ocean to the South Indian Ocean despite ALB tuna environmental frontiers being absent in South African waters. More fishing may explain the higher CPUE zones between $35^{\circ} \mathrm{E}-40^{\circ} \mathrm{E}$ and $50^{\circ} \mathrm{E}-55^{\circ} \mathrm{E}$ in June-July and August, respectively. These results suggest the presence of two types of fishing grounds, consisting of a coastal fishing ground at $30^{\circ} \mathrm{S}-40^{\circ} \mathrm{S}$ and $20^{\circ} \mathrm{E}-40^{\circ} \mathrm{E}$ (south of Madagascar) and a deep-sea fishing ground at $30^{\circ} \mathrm{S}-40^{\circ} \mathrm{S}$ and $60^{\circ} \mathrm{E}-100^{\circ} \mathrm{E}$. Furthermore, Wang et al. [1] reported two types of fishing grounds for ALB tuna in the Indian Ocean, consisting of the upwelling coast of Madagascar and an area at $20^{\circ} S-40^{\circ} S$ and $60^{\circ} \mathrm{E}-100^{\circ} \mathrm{E}$, which supports the current results. Changes in SST may be the most important reason for changes in latitudinal and longitudinal spatial distributions. Studies have also reported changes in the movement of ALB tuna in different latitudes and longitudes if the SST exceeds the species thermal tolerance in the Indian Ocean [33]. Moreover, researchers have indicated that tropical ALB tunas remain in shallower, warmer water at night and deeper, cooler water during the day. These results indicate that ALB tuna favor a vertical distribution. Figure 15 displays the predicted CPUE values from March to August; the maximum predicted CPUE value occurred at $35^{\circ} S-40^{\circ} S$ and $25^{\circ} S-35^{\circ} S$ in March-May and June-August, respectively. In March-May, the zone with a higher prediction value had limited coverage. However, it began shifting northward in June and reached $25^{\circ} \mathrm{S}$ by the end of August. The predicted results were highly correlated with a range of crucial environmental factors, including SST, SSS, and SSC. Longitudinally, a higher ALB tuna prediction was also observed at $100^{\circ} \mathrm{E}-120^{\circ} \mathrm{E}$, but the standardized CPUE did not exhibit any spatial distribution, possibly because of suitable environmental factors and no effort made by the tuna to migrate.

Other factors may also have a critical effect on the seasonal spatial distribution of ALB tuna in the Indian Ocean. Availability of prey can be considered a vital factor. Some studies have reported preliminary findings on this subject. Glaser [35] quantified the abundance of juvenile ALB tuna in the California current system based on the predation rate on northern anchovy and concluded that ALB tuna may remove nearly $1 \%$ to slightly over $17 \%$ of anchovy recruitment biomass annually. The lunar phase may also be a crucial factor in ALB tuna abundance. For example, Akyol and Ceyhan [36] discussed the effect of the lunar phase on the CPUE of Turkish ALB tuna gillnet fisheries and concluded that dark periods $(114.4 \pm 21.9)$ had a higher mean CPUE than did light periods $(66.8 \pm 8.7)$. Our study on the fishery oceanography of ALB tuna in the southern Indian Ocean provided valuable insight into the different factors affecting the catch rate of ALB tuna. Future studies should investigate the habitat hotspots of ALB tuna. A habitat hotspot is a region with a higher abundance of a given species. Furthermore, the effects of prey availability and the lunar phase on the Indian Ocean ALB tuna warrant further investigation. The associations of oceanic hotspots with hydrographic frontal zones, features, and eddy fields strongly influence the distribution pattern and formation of tuna abundance [32]. Increased knowledge regarding habitat hotspots would improve habitat protection and tuna fishery management. Enhancing the understanding of the spatial dynamics, connectivity, and relevant environmental factors for ALB tuna are key to improving species management [37]. Large-scale tagging and sampling programs at appropriate locations and periods are crucial for each ocean basin that covers the major fishery stocks because they can help to clarify the distribution and spatial dynamics of ALB tuna and the effects of different environmental factors on the stocks, which are difficult to determine because of the varying distribution of ALB tuna throughout water columns [12].

\section{Conclusions}

The present study provides information on some key environmental factors that spatially and temporally affect the habitat of ALB tuna in the southern Indian Ocean. The catch rate and distribution of ALB tuna were highly correlated with the variability of the oceanographic conditions in the southern Indian Ocean. Statistical analysis revealed that standardized CPUE was positively correlated with SST, SSC, EKE, and SSH but negatively correlated with SSS and MLD. Among all of the environmental factors studied, SST explained the most deviation, followed by SSS and SSC. These three factors explained over $40 \%$ of the total deviance. ALB tunas were mainly distributed between $20^{\circ} \mathrm{E}$ to $110^{\circ} \mathrm{E}$ and $25^{\circ} \mathrm{S}$ to $40^{\circ} \mathrm{S}$. Regions with an SST of $18.5^{\circ} \mathrm{C}$, SSS of $35.5 \mathrm{psu}$, and SSC of $0.15 \mathrm{mg} / \mathrm{m}^{3}$ displayed the maximum centralized abundance. Model-6, which had the lowest AIC value, was used to predict the CPUE in 2015. The predicted CPUE revealed that the potential fishing zone was $35^{\circ} \mathrm{S}-40^{\circ} \mathrm{S}$ and $25^{\circ} \mathrm{S}-35^{\circ} \mathrm{S}$ during March and April to August, respectively. Further research will be conducted on the effect of different oceanic fonts on the abundance, to construct a habitat 
suitability model to clarify ALB tuna abundance in the present study area over the same study period.

Our study of the fishery oceanography of ALB tuna in the southern Indian Ocean provides valuable insight into the different factors affecting the catch rate of ALB tuna. Aside from minor discrepancies, our results regarding the oceanographic conditions favored by ALB tuna are generally consistent with those of other studies. Comprehensive knowledge regarding the distribution pattern of ALB tuna is necessary for the sustainable use of natural and unique resources.

\section{Author contributions}

"Conceptualization, S.M and M.A.L.; methodology, M.A.L and S.M.; software, S.M.; validation, M.A.L.; formal analysis, S.M.; investigation, M.A.L., Y.C.W. and J.W.C; resources, M.A.L. and Y.C.W.; writing-original draft preparation, S.M.; writing -review and editing, M.A.; visualization, Y.C.W.; All authors have read and agreed to the published version of the manuscript."

\section{Funding}

This research was financed by the Taiwan Council of Agriculture (106AS-10.1.5-FA-F1 (4); 107AS-9.1.5FA-F1 (4)) and the Ministry of Science and Technology of Taiwan (MOST105-2611-M-019-011).

\section{Declaration of competing interest}

There was no conflict of interest.

\section{Acknowledgments}

We thank the valuable comments and suggestions from the three anonymous reviewers and the editor, as well as the team members of the Fisheries Agency (FA), and the Overseas Fisheries Development Council (OFDC) of Taiwan for their assistance in data preparation. We are grateful to the Council of Agriculture, Taiwan, R.O.C., for the grant. We also acknowledge Wallace Academic Editing Company for editing this manuscript. We also acknowledge Wallace Academic Editing for editing this manuscript.

\section{Appendix}

\section{Supplementary Materials}

SF 1: Changes in monthly SST in the study area from Mach to August 2009-2014, SF 2: Changes in monthly SSS in the study area from Mach to August 2009-2014,
SF 3: Changes in monthly in the study area from Mach to August 2009-2014, SF 4: Changes in monthly MLD in the study area from Mach to August 2009-2014, SF 5: Changes in monthly EKE in the study area from Mach to August 2009-2014, SF 6: Changes in monthly SSH in the study area from Mach to August 2009-2014, SF 7: Changes in monthly CPUE in the study area from Mach to August 2009-2014.

\section{References}

[1] Wang J, Zhu J, Chen X. Spatiotemporal distribution of albacore in relation to oceanographic variables in the Indian Ocean. 2019.

[2] Collette BB, Nauen CE. Scombrids of the world: an annotated and illustrated catalogue of tunas, mackerels, bonitos, and related species known to date. v. 2. 1983.

[3] Miyake PM. A brief history of the tuna fisheries of the world. In: Second meeting of the technical advisory committee of the FAO project management of tuna fishing capacity: conservation and socio-economics. vol. 2. FAO Fish. Proc.; 2005. p. $23-50$.

[4] Podesta GP, Browder JA, Hoey JJ. Exploring the association between swordfish catch rates and thermal fronts on US longline grounds in the western North Atlantic. Continent Shelf Res 1993;13(2-3):253-77.

[5] Schick RS, Goldstein J, Lutcavage ME. Bluefin tuna (Thunnus thynnus) distribution in relation to sea surface temperature fronts in the Gulf of Maine (1994-96). Fish Oceanogr 2004;13(4):225-38.

[6] Laurs RM, Fiedler PC, Montgomery DR. Albacore tuna catch distributions relative to environmental features observed from satellites. Deep Sea Res Part A Oceanographic Research Papers 1984;31(9):1085-99.

[7] Polovina JJ, Howell E, Kobayashi DR, Seki MP. The transition zone chlorophyll front, a dynamic global feature defining migration and forage habitat for marine resources. Prog Oceanogr 2001;49(1-4):469-83.

[8] Zainuddin Mukti, Saitoh Katsuya, Saitoh Sei-Ichi. Albacore (Thunnus alalunga) fishing ground in relation to oceanographic conditions in the western North Pacific Ocean using remotely sensed satellite data. Fish Oceanogr 2008;17.2: 61-73.

[9] Lan KW, Kawamura H, Lee MA, Lu HJ, Shimada T, Hosoda K, et al. Relationship between albacore (Thunnus alalunga) fishing grounds in the Indian Ocean and the thermal environment revealed by cloud-free microwave sea surface temperature. Fish Res 2012;113(1):1-7.

[10] Zainuddin M, Kiyofuji H, Saitoh K, Saitoh. S.I. Using multisensor satellite remote sensing and catch data to detect ocean hot spots for albacore (Thunnus alalunga) in the northwestern North Pacific. Deep Sea Res Part II Top Stud Oceanogr 2006;53(3-4):419-31.

[11] Hoyle SD, Fu D, Kim DN, Lee SI, Matsumoto T, Satoh K, et al. Collaborative study of albacore tuna CPUE from multiple Indian Ocean longline fleets in. IOTC-2019-WPTmT, AS-10. 2019.

[12] Nikolic N, Fonteneau A, Hoarau L, Morandeau G, Puech A, Bourjea J. Short review on biology, structure, and migration of Thunnus alalunga in the Indian Ocean. IOTC, IOTC-2014-WPTmT05-13 Rev_2. 2014.

[13] Bigelow K, Hampton J, Miyabe N. Application of a habitatbased model to estimate effective longline fishing effort and relative abundance of Pacific bigeye tuna (Thunnus obesus). Fish Oceanogr 2002;11:143e155.

[14] Bigelow K, Maunder M, Hinton M. Comparison of deterministic and statistical habitat-based models to estimate effective longline effort and standardized cpue for bigeye and yellowfin tuna. SCTB16 working paper; 2003. RG-3. 
[15] Wood SN. Generalized additive models: an introduction with R. Boca Raton, FL: Chapman and Hall: CRC Press; 2004.

[16] Fonteneau A. An overview of Indian Ocean albacore: fisheries, stocks and research. In: IOTC working party on temperate tunas, IOTC-WPTmT-02; 2004.

[17] Chen IC, Lee PF, Tzeng WN. Distribution of albacore (Thunnus alalunga) in the Indian Ocean and its relation to environmental factors. Fish Oceanogr 2005;14(1):71-80.

[18] Michael R, Lynn J. Seasonal migration of North Pacific albacore, Thunnus alalunga, into North American coastal waters: distribution, relative abundance, and association with Transition Zone waters. Fish Bull 1977;75(4).

[19] Lehodey P, Senina I, Murtugudde R. A spatial ecosystem and populations dynamics model (SEAPODYM) - Modeling of tuna and tuna-like populations. Prog Oceanogr 2008;78(4):304-18.

[20] Lee MA, Vayghan AH, Liu DC, Yang WC. Potential and prospective seasonal distribution of hotspot habitat of albacore tuna (Thunnus alalunga) in the South Indian Ocean using the satellite data. IGARSS; 2017. p. 5747-50.

[21] Roberts PE. Surface distribution of albacore tuna, Thunnus alalunga Bonnaterre, in relation to the Subtropical Convergence Zone east of New Zealand. N Z J Mar Freshw Res 1980;14(4):373-80.

[22] Novianto D, Susilo E. Role of sub surface temperature, salinity and chlorophyll to albacore tuna abundance in Indian ocean. Indones Fish Res J 2016;22(1):17-26.

[23] Arrizabalaga Haritz, Dufour Florence, Kell Laurence, Merino Gorka, Ibaibarriaga Leire, Chust Guillem, et al. Global habitat preferences of commercially valuable tuna. In: Deep sea research Part II: topical studies in oceanography. vol. 113; 2015. p. 102-12.

[24] Xu Y, Teo SL, Holmes J. An update of the standardized abundance index of US and Canada albacore troll fisheries in the North Pacific (1966-2012). ISC/13/ALBWG-03/06. In: Work. Pap. Submitt. To ISC albacore work. Gr. Work. 5-12 november; 2013.

[25] Belloc G. Sur la sexualité du germon et l'existence probable d'un lieu de ponte près de Madère. Rev Trav Inst Pêches Mar 1937;X(3):347-51.

[26] Briand K, Molony B, Lehodey P. A study on the variability of albacore (Thunnus alalunga) longline catch rates in the southwest Pacific Ocean. Fish Oceanogr 2011;20(6):517-29.
[27] Williams AJ, Allain V, Nicol SJ, Evans KJ, Hoyle SD, Dupoux C, et al. Vertical behavior and diet of albacore tuna (Thunnus alalunga) vary with latitude in the South Pacific Ocean. Deep Sea Res Part II Top Stud Oceanogr 2015;113: 154-69.

[28] Childers J, Snyder S, Kohin S. Migration and behavior of juvenile North Pacific albacore (Thunnus alalunga). Fish Oceanogr 2011;20(3):157-73.

[29] Cosgrove R, Arregui I, Arrizabalaga H, Goni N, Neilson JD. Predation of pop-up satellite archival tagged albacore (Thunnus alalunga). Fish Res 2015;162:48-52.

[30] Kimura S, Sugimoto MNAT. Migration of albacore, Thunnus alalunga, in the North Pacific Ocean in relation to large oceanic phenomena. Fish Oceanogr 1997;6(2):51-7.

[31] Daqamseh ST, Pradhan B, Al-Oraiqat A, Habib M. MODIS derived sea surface salinity, temperature, and chlorophyll-a data for potential fish zone mapping: west red sea coastal areas, Saudi Arabia. Sensors 2019;19(9):2069.

[32] Zainuddin M, Saitoh SI, Saitoh K. Detection of potential fishing ground for albacore tuna using synoptic measurements of ocean color and thermal remote sensing in the northwestern North Pacific. Geophys Res Lett 2004 $31(20)$

[33] Dueri S. Impacts of climate change and ocean acidification on Indian Ocean tunas. 2017.

[34] Beardsley Jr GL. Distribution and apparent relative abundance of yellowfin tuna (Thunnus albacares) in the eastern tropical Atlantic in relation to oceanographic features. Bull Mar Sci 1969;19(1):48-56.

[35] Glaser SM. Do albacore exert top-down pressure on northern anchovy? Estimating anchovy mortality because of predation by juvenile north pacific albacore in the California current system. Fish Oceanogr 2011;20(3):242-57.

[36] Akyol O, Ceyhan T. Moon phase's influence on CPUE of Turkish albacore gillnet fishery. Collect vol sci pap Icca 2012; 68(2):499-502.

[37] Hsu CC. The status of Indian ocean albacore-A review of previous work. Proceedings of the fifth expert consult on Indian ocean tunas. Indo-pacific tuna development and management programme. Coll Vol Work Doc 1994;8: 117-24. 